\title{
O OFICIAL X O OFICIOSO NO SERVIÇO NOTURNO: A QUEM INTERESSA ESTA PRÁTICA
}

\author{
Vera Regina S. Sobral * \\ Sérgio Correia Marques ** \\ Rosangela Guiomar A. Mariz ** \\ Marcos Monteiro ${ }^{* *}$
}

\begin{abstract}
RESUMO - Baseado no conceito de assistência de enfermagem, procura identificar no serviço noturno de um hospital práticas que contribuem para melhorar esta assistência. Conclui que as mesmas são mecânicas, centradas nas tarefas e que as ações do pessoal de enfermagem se concentram em apenas dois horários.
\end{abstract}

ABSTRACT - Based on the concept of Nursing assistance, this work try to identify in the night service in one hospital, practices that contribute to improve this assistance. It concludes that these practices are mechanicale, centered on tasks and that the actions of the nursing personnel are concentrated in only two hours.

\section{INTRODUÇÃO}

A assistência de enfermagem desenvolvida no serviço noturno (SN) deve dar continuidade ao que é planejado no serviço diurno (SD), onde um maior número de profissionais pode avaliar de forma mais acurada as necessidades dos pacientes. Entretanto, para uma assistência de enfermagem ser eficiente e eficaz, ela necessita ser avaliada constantemente no seu planejamento; isto é, sempre que o paciente apresentar qualquer alteração em suas necessidades básicas ou quando houver algum problema de ordem administrativa.

É bom lembrar que a doença sua evolução e/ou involução, bem como os problemas administrativos não escolhem hora para acontecer.

Acredita-se que o número menor de componentes da equipe de enfermagem do $\mathrm{SN}$ se deve ao fato de que a noite seja o período adequado para o sono e ao repouso e assim um número de ações menor de enfermagem sejam desenvolvidas junto aos pacientes. Se isto é correto, também é o fato de que à noite é o momento onde o paciente mais sente a distância do seu ambiente socio-familiar, tornando-se mais carente afetivamente e, portanto, necessitando de uma assistência emocional também.

Por outro lado, o induvíduo que trabalha durante a noite tem contra si pelo menos dois fatores naturais:
0 primeiro é a necessidade de readaptar seu organismo à permanecer acordado e atento no período no qual com certeza foi educado para dormir e repousar; e o segundo é o de trabalhar sob a luz artificial. Nas duas situações há um prejuizo acentuado da saúde e bem provável do reflexo e raciocínio. Ao se planejar a quantidade de recursos humanos para trabalhar no SN, bem como a assistência de Enfermagem a ser prestada nesse período esses fatores devem ser levados em conta para que não haja prejuízo na qualidade da assistência.

A partir de uma observação assistematizada e um pouco mais atenta das prescrições de enfermagem e dos horários de medicações do SN de um Hospital Universitário, detectou-se uma concentração, maior de trabalho, especificamente em dois horários distintos, que levou os autores a discussões e reflexões sobre o fato até porque os registros de Enfermagem atestam a implementação da quase totalidade das tarefas nestes respectivos horários. Diante de uma questão tão relevante optou-se por um plano de estudos sobre 0 assunto. Como ponto de partida decidiu-se conhecer as opiniões tanto das chefes de enfermagem das unidade envolvidas quanto das equipes de enfermagem do SN sobre a assistência de enfermagem desenvolvida no referido horário. É importante ressaltar que esta assistência tem sido marginalizada pelos estudiosos já que pouca atenção tem recebido.

\footnotetext{
* Enfermeira do HUPE RJ

** Enfermeiros Supervisores de HUPE RJ
} 
Este trabalho não tem a pretensão de esgotar o assunto mas somente trazer para discussão algumas observações sobre a prática de enfermagem desenvolvida no SN de um Hospital Universitário o qual tem valorizado a assistência individualizada do paciente.

\section{LITERATURA}

\section{HORTA (1973) relata que:}

Com o desiquilíbrio homeodinãmico dos fenômenos vitais surgem certas tensões no ser humano denominadas Necessidades Humanas Básicas. Estas necessidades são latentes e se apresentam variando de intensidade de acordo com o grau de desequilíbrio. Não existe fundamentalmente satisfação completa destas necessidades, se houvesse, a motivação individual não existiria.

As necessidades se inter-relacionam e se manifestam por sinais e sintomas e a enfermagem deve estar atenta a isto, pois a satisfação de uma esta geralmente ligada a outra.

Daí, segundo HORTA, a importãncia do Histórico de Enfermagem. Dados precisos, sem repetições que permitam a compreensão e a prestação imediata de cuidados individualizados. Só a enfermeira faz o Histórico, de preferencia através de entrevista informal. A observação, o exame físico e a explicação do que vai ser feito e porque ajudam na inter-relação enfermeiro/paciente e devem ser feitos na admissão.

Fatores relacionados o cliente/profissional e ou instituição podem interferir no Histórico.

Se o objeto maior da instituição é o paciente, o trabalho da enfermagem é favorecido, facilitando da execução do processo de Enfermagem.

A quantidade e qualidade do pessoal de Enfermagem também interferem no Processo de Enfermagem.

A identificação e levantamento dos hábitos da vida do paciente são importantissimos, pois, como afirma HORTA (1973) fornecem subsídios para o planejamento da assistência, através do conhecimento das necessidades básicas do mesmo.

A prescrição de Enfermagem ou Plano de Cuidados exige um aprazamento de horário, além de ser feito diariamente. Ele é o coordenador da Equipe de Enfermagem na assistência adequada à necessidade básica do paciente. A prescrição também deve ser clara, precisa, e ter listados os cuidados prioritários. Deve ser checada ao ser realizada e o registro de Observação referente às avaliações do cuidado executado também deve ser feito.

Além de todas as etapas já descritas, a autora ressalta a necessidade de um "relato diário ou periódico das mudanças sucessivas que ocorrem no ser humano enquanto estiver sobre assistência do profissional'. É a Evolução de Enfermagem. Dela podem surgir mudanças no Plano Assistêncial e no Plano de Cuidados que visam a melhoria da assistência e a elevação do nível de atendimento qualitativo e quantitativo, além de fornecer dados para a supervisão do pessoal auxiliar.

SANTOS (1985) refere o Hospital como uma empresa que presta serviços, porém, diferenciados das demais em razão da natureza de sua produção que é a assistência ao ser humano na condição de paciente. Este tipo de empresa também desenvolve as atividades de ensino e pesquisa direcionadas para o bem estar do ser humano. Portanto é uma organização que reune pessoas e materiais engrenados para um único fim o paciente.

Voltando-se para 0 aspecto assistêncial, trata da necessidade de sistematizar ações para serem desempenhadas pela equipe de enfermagem, de forma a conduzir o paciente ao seu autocuidado, diferenciando esta equipe das demais por suas características próprias de observação, discernimento e divisão de trabalho. E esta equipe é formada por elementos que se diferenciam quanto ao nível de escolaridade, formação profissional e ocupacional, tendo como líder aquele mais qualificado e cuja função é planejar o trabalho de acordo com a capacidade do executor e o nível de complexidade das ações.

KRON (1978) aponta um descompasso entre o perfil do estudante de enfermagem, que segundo as escolas, deve primar por uma assistência individualizada e o perfil da enfermeira exigido pelas instituições hospitalares que é "orientado para a tarefa". Desta forma, ao se formar a enfermeira sofre um impacto com o que lhe é apresentado e proposto a desempenhar podendo absorver rapidamente, até por necessidade de sobrevivência profissional a prática da tarefista.

Adiante, a autora, enfatiza que vários estudos deixam claro que os pacientes se preocupam mais em ter suas necessidades básicas satifeitas e que as enfermeiras acreditam que o mais importante é "ministrar medicação e tratamento na hora certa".

KRON (1978) acredita que para se prestar uma assistência individualizada ao paciente pressupõe um conhecimento e compreensão do indivíduo como um todo e portanto de suas necessidades básicas afetadas. A partir daí é possível planejar e intervir coerente com os princípios da qualidade.

Em relação a normas e rotinas que orientam as ações de enfermagem a autora salienta que a sua utilização implica em um discernimento e reflexão da situação a ser avaliada. A isto equivale dizer que normas e rotinas não substituem a tomada de decisão e que o respeito radical a elas implica em assistência de enfermagem ineficiente.

KRON (1978) assegura que a implementação do que foi planejado pela enfermeira necessita de uma comunicação clara e objetiva com a equipe, uma prescrição de enfermagem precisa e de fácil entendimento, e da consciência de que a equipe é formada por seres humanos e particularmente com qualidades e habilida- 
des diferenciadas. Ao delegar ações de enfermagem à equipe a enfermeira deve assegurar a sua condição de coordenadora da assistência prestada, como forma de garantir uma assistência de enfermagem individualizada.

CARVALHO (1979) refletindo sobre a prática da enfermagem no Brasil considera a posição da enfermeira como crítica e destaca três razões principais como causa quais sejam: assistência voltada para a doença de comum acordo com as metas institucionais, serviço tecnicista centrado em tarefas, sem crítica, pouca qualificação profissional onde a enfermeira assume simplesmente a distribuição das atividades à equipe negligenciando a implementação da metodologia da assistência; e a assunção de cargos administrativos que se afasta dos cuidados diretos ao paciente com consequente perda de autonomia na equipe de saúde.

\section{METODOLOGIA}

A metodologia constou, em primeiro lugar, da seleção das Unidades de Internação (U.Is) com maior demanda das ações de enfermagem detectada a partir de uma busca atenta dos prontuários dos pacientes. Assim selecionou-se cinco U.I. que aqui são chamadas Unidades A, B, C, D e E que têm como média de internação vinte pacientes.

Em segundo lugar listou-se as ações de enfermagem desenvolvidas bem como as medicações e seus respectivos horários com o objetivo de se conhecer os horários onde há uma maior concentração de trabalho.

Em terceiro lugar entrevistou-se individualmente as chefias de enfermagem e os componentes das equipes de enfermagem dos SNs das referidas U.I. para se saber como eles vêem o desenvolvimento da prática de enfermagem deste horário de serviço. A entrevista constou de questões abertas.

Posteriormente analisou-se as opiniões colhidas fazendo-se uma comparação com a demanda de trabalho detectada.

O Hospital Universitário em estudo tem uma carga horária de trabalho para o serviço noturno de 12/60 h com uma complementação de carga horária.

\section{A PRÁtICA DE ENFERMAGEM NO SERVIC̣O NOTURNO}

\section{Dos Achados}

O Hospital Universitário em estudo tem, no SN, enfermeiras apenas nas Unidades especializadas ficando o restante das unidades a cargo de quatro enfermeiros supervisores que cobrem respectivamente os quatro andares do hospital. As Unidades de Internação que foram alvo deste trabalho não são especializadas ficando, portanto, a assistência de enfermagem coordenada por uma supervisora.
A maioria das enfermeiras chefes da U.I. envolvidas no estudo afirma que o número de auxiliares de enfermagem não é suficiente para desenvolver uma assistência compatível com as reais necessidades dos pacientes. Alegam que o número de pacientes é grande sendo que a maior parte deles é totalmente dependente e ainda, que as intercorrências que fogem à rotina prejudicam o andamento do serviço e conseqüentemente decai a qualidade da assistência. Elas acreditam que se nas equipes contassem com mais um auxiliar esse problema seria minimizado. Uma enfermeira acredita que o número de funcionários é suficiente exceto se houver paciente grave.

A quase totalidade das enfermeiras atesta não acreditar que os cuidados de enfermagem prescritos sejam executados principalmente nos horários aprazados em decorrência dos motivos já expostos acima. Apenas uma enfermeira acredita que as atividades são feitas nos horários aprazados quando não há intercorrência.

Quatro das cinco enfermeiras entrevistadas têm críticas sobre o desempenho das equipes de enfermagem dos SN. Uma relata que por vezes os pacientes se queixam do atendimento e que, com certeza, muitas vezes certos cuidados não são prestados; outra acredita que uma equipe do SN não está desempenhando bem as suas funções e que talvez haja necessidade de um remanejamento; entende ainda que os registros são falhos, pois nem tudo que é feito é relatado; uma outra também faz críticas à qualidade dos registros que os considera suscintos demais; observa que tem orientado as suas equipes sempre que é possível. Uma última aponta que alguns auxiliares de enfermagem se prevalecem do seu número insuficiente para não executar determinadas tarefas. Apenas uma enfermeira não teve qualquer crítica a fazer.

Quanto ao horário para descanso a maioria das enfermeiras chefes das U.I afirma que ele é necesário para que o funcionário continue produzindo. Uma delas assegura que o SN é muito desgastante e que o descanso é indispensável. Entretanto, uma enfermeira entende que não deve haver horário de descanso e que o mesmo deve ser of icioso ou seja quando houver condições para tal já que por experiência observou que muitos auxiliares de enfermagem descansam sem avaliar as reais condições da Unidade e quando da passagem de plantão se detecta algum problema como por exemplo algo por fazer a equipe alega falta de tempo. A quase totalidade das enfermeiras assegura que existem cuidados e medicações os quais poderiam ser aprazados em outros horários que não os das $22 \mathrm{~h}$ e $6 \mathrm{~h}$ e que elas procuram sempre não sobrecarregar o SN e principalmente, o horaŕio das $6 \mathrm{~h}$ quando a coleta de sangue, que nesse hospital é feito pela enfermagem, prejudica muito a execução dos cuidados aprazados para este horário. Uma alegou não ser possível uma mudança nesses aprazamentos. E uma outra se responsabiliza pela sobrecarga de trabalho nos horários citados por serem 
seus aprazamentos feitos mecanicamente sem planejamento algum.

A totalidade das equipes de enfermagem do SN considera que o número de auxiliares de enfermagem é insuficiente e aponta causas, consequências e alternativas de solução. Como causas há o absenteismo, licenças e férias sem a devida cobertura o que, segundo as equipes, prejudicam muito o bom andamento do serviço. Como consequência há uma queda da qualidade da assistência já que o número de cuidados é muito grande não sendo possível sua realização nos horários aprazados e nem a utilização do tempo realmente necessário para executá-los. Sugerem que haja pelo menos mais um auxiliar de enfermagem em cada equipe e/ou que as supervisoras tenham a sua disposição alguns auxiliares de enferagem sem escala prévia para que elas os distribuam onde for necessário.

A maioria das equipes de enfermagem do $\mathrm{SN}$ afirma que muitos cuidados prescritos para um determi- nado horário poderiam ser aprazados para outro, evitando acúmulo de tarefas. Está consciente de que não consegue executar o que é prescrito nos devidos horários e questiona, por exemplo, por que "um determinado paciente que nunca apresentou elevaçã térmica precisa ter sua temperatura aferida as $22 \mathrm{~h}$ ?" Aponta também, a coleta de sangue das $6 \mathrm{~h}$ como atribuição que não é da enfermagem mas que neste hospital é feita por ela e que, em geral, demanda muito tempo para ser realizada sempre em detrimento de outras atividades.

Todas as equipes de enfermagem do $\mathrm{SN}$ foram unânimes em considerar os horários de $22 \mathrm{~h}$ e $6 \mathrm{~h}$ como os de maior acúmulo de trabalho.

Para facilitar a compreensão deste fato elaborouse o quadro abaixo.

QUADRO 1 - Demonstrativo da quantidade de medicações e de cuidados de enfermagem aprazados para as $22 \mathrm{~h}$ e $6 \mathrm{~h}$ nas U.I pesquisadas.

\begin{tabular}{|c|c|c|c|c|c|c|c|c|c|c|}
\hline \multicolumn{7}{|c|}{ HORA } & \multicolumn{3}{|c|}{$22 \mathrm{~h}$} & \multicolumn{5}{c|}{$6 \mathrm{~h}$} \\
CUIDADOS U.I. & A & B & C & D & E & A & B & C & D & E \\
\hline Medicação Oral & 28 & 39 & 47 & 32 & 10 & 24 & 22 & 18 & 19 & 12 \\
\hline Medicação Parenteral & 15 & 06 & 09 & 05 & 11 & 16 & 10 & 05 & 04 & 11 \\
\hline Cuidados Gerais & 44 & 27 & 27 & 30 & 21 & 21 & 31 & 10 & 20 & 22 \\
\hline Total & 87 & 72 & 83 & 67 & 42 & 61 & 63 & 33 & 43 & 45 \\
\hline
\end{tabular}

No quadro acima considerou-se como cuidados gerais a aferição de sinais vitais, nebulizações, mudança de decúbito, glicosúria, aplicações quentes e frias para curva térmica e coleta de sangue para glicemia.

Além destes cuidados que estavam aprazados nas prescrições dos pacientes somam-se aqueles que rotineiramente são executados como - tapotagem, exercícios respiratórios, balanço hídrico, preparo e administração da hidratação venosa, coleta de sangue para exames, preparo para exames, higienização do paciente, organização da unidade do paciente, organização do posto de enfermagem e registro de enfermagem.

Quanto ao horário para descanso todas as equipes foram unânimes em afirmar a sua necessidade em caráter oficial e em lugar adequado. Alegaram, entretan- to, que às vezes, o acúmulo de serviços é tamanho que se torna inviável o descanso.

\section{DISCUSSÃo}

Em linhas gerais parece haver uma concordância entre as opiniões das enfermeiras chefes das U.I. e das equipes de enfermagem do SN. Em sua maioria o grupo como um todo considera que o número de auxiliares de enfermagem que compõem as equipes de enfermagem do SN não é suficiente; que os cuidados de enfermagem prescritos e executados fogem aos horários aprazados; que alguns cuidados de enfermagem $\mathrm{e}$ medicações poderiam receber outros horários de apra- 
zamento que não os 22:00 e 06:00 h; que a coleta de sangue não é tarefa da enfermagem e a sua execução prejudica a implementação da assistência e que é necessário um horário de descanso em lugar adequado. Mas a quem interessa essa concordância de opiniões e essa prática incoerente, caótica, acrítica, tarefista, onde o que é oficioso é o que realmente acontece e 0 que é oficial é o que está escrito?

Qual a lógica, teoria ou mecanismo que norteia as enfermeiras a continuarem a prescrever cuidados tendo consciência de que se eles forem executados o serão em outros horários que não os aprazados?

É possível que a enfermeira prescreva cuidados de enfermagem porque acredita na sua importância para eficiência e eficácia da assistência de enfermagem a ser prestada; ou por uma questão de status profissional já que nesse hospital existe uma folha única de prescrição onde qualquer profissional de nível superior (enfermeira, médico, psicólogo, entre outros) após prescrever deve assinar e carimbar; ou ainda porque a filosofia do serviço de enfermagem da instituição preconiza e valoriza a assistência individualizada ao paciente estimulando e cobrando das enfermeiras a sua prática. Ainda pode acontecer dos três fatores estarem presentes. Porém, independente da (s) causa (s) detectou-se que se há um planejamento da assistência de enfermagem ele é distanciado tanto das necessidades dos pacientes quanto da quantidade e qualidade dos componentes das equipes de enfermagem comprometendo sobre maneira a qualidade da assistência.

Quanto aos aprazamentos dos cuidados e das medicações para ás $22 \mathrm{~h}$ e $6 \mathrm{~h}$ presume-se que isto ocorra devido ao fato de que esses horários sejam, senão oficialmente mas pelo menos oficiosamente, padronizados pelo serviço. Assim, no momento em que as enfermeiras aprazam as prescrições elas simplesmente seguem uma rotina de horário produzindo uma assistência de enfermagem mecanicista, rotinizada e desatenta quanto à satisfação das necessidades dos pacientes e quanto à sobrecarga de trabalho para a equipe.

Embora algumas enfermeiras afirmem procurar não sobrecarregar o SN principalmente no horário das $6 \mathrm{~h}$; os auxiliares de enfermagem negam esse fato o que encontra respaldo no Quadro 1. Quando o auxiliar de enfermagem pergunta por que aferir, às $22 \mathrm{~h}$, a temperatura de um paciente que ainda não apresentou qualquer alteração em sua curva térmica parece claro haver uma total pertinência neste questionamento. A resposta mais adequada talvez passe por um " planejamento" rotinizado e acrítico.

Além dos cuidados aprazados existem outros que sâo feitos rotineiramente nos mesmos horários, bem como outras atividades de enfermagem que são atribuições das equipes do SN (organização da unidade do paciente e do posto de enfermagem, preparo de medicações, controle e observação de hidratação venosa, balanço hídrico, registros, etc.) assim como atendimento imediato a necessidades dos pacientes que contribuem substancialmente para o crescimento do binômio sobrecarga de trabalho $\mathbf{x}$ deficiência de pessoal.

Uma questão de extrema relevância se apresenta. Se enfermeiras e auxiliares de enfermagem criticarem o acúmulo de atividades nos horários das das $22 \mathrm{~h}$ e $6 \mathrm{~h}$ eles realizam outros cuidados e/ou atividades ao mesmo tempo que desempenham àqueles aprazados. Assim, caracteriza-se ainda mais o desenvolvimento da assistência de enf ermagem como uma prática mecanicista e rotinizada.

Outra questão de extrema relevância se apresenta. Se enfermeiras e auxiliares de enfermagem reconhecem que alguns cuidados prescritos não são executados ou pelo menos não nos horários aprazados, que critérios as equipes de enfermagem utilizam para excluir ou não algum cuidado e/ou estabelecer a sequência de atividades a serem desenvolvidas?

0 estudo não clarificou esta situação. Entretanto, pode-se supor que estes critérios estejam relacionados às condições de cada paciente, às intercorrências que porventura aconteçam e à quantidade de componentes da equipe. Porem, na medida em que as enfermeiras asseguram que a maioria dos pacientes são totalmente dependentes dos cuidados de enfermagem, pode-se questionar a validade ou a pertinência desses critérios. É possível também que o planejamento da assistência de enfermagem não esteja sendo feito conforme preconiza a literatura consultada ou ainda, que os auxiliares de enfermagem não estejam bem orientados para a implementação de sua prática.

Quando a chefia de enfermagem cobra das chefes de unidades a assistência individualizada ela recebe em troca evoluções e prescrições de enfermagem assinadas e carimbadas. As enfermeiras, por sua vez, passam a cobrar dos auxiliares de enfermagem os registros mais detalhados, pois eles são a prova substâncial da realização do trabalho. Este pressuposto inviabiliza a qualidade da assistência porque nega a observãncia dos elementos envolvidos na sua metodologia.

A observação dos autores da prática realizada revela a necessidade que a equipe tem de adequar, de alguma forma, o que é preciso ser feito com o tempo e os recursos humanos disponíveis. Utilizam, então, uma lógica mecanicista, tarefista, de objetivos imediatistas onde não há tempo nem lugar para uma assistência humanizada.

Ao assumir o plantão os auxiliares de enfermagem partem para o cotrole de material e de psicotrópico, a implementação dos cuidados prescritos e o preparo da medicação de todo o período e das etapas de hidratação venosa. É um trabalho manual, de habilidade e que parece dispensar o raciocínio. A explicação dada pelos auxiliares de enfermagem do porque de toda medicação do período noturno ser preparada num mesmo momento é sempre a economia de tempo haja vista que às 06:00 h é grande o número de atribuições 
principalmente a coleta de sangue que demanda muito tempo.

É preciso deixar claro que não se entende como Hospital Universitário cuja filosofia do serviço de enfermagem é a assistência individualizada ao paciente, permite que seja a equipe de enfermagem responsável pela coleta de sangue bem como o encaminhamento de todo o material para exames.

Este desenvolvimento atribulado de tarefas e $o$ ir e vir do posto de enfermagem ao leito do paciente e vice-versa parece massificaqr a assistência robotizando a equipe. Desta forma qualquer intercorrência quebra a continuidade da rotina descaracterizando ainda mais a qualidade da assistência. Um fato que comumente ocorre e que tanto foi observado pelos autores como apontado pelos auxiliares e que ratifica o exposto no parágrafo acima é a questão da higienização do paciente em consequência das situações em que fazem a rotina como por exemplo as eliminações no leito. A troca de roupa do paciente não é entendida pelos auxiliares de enfermagem como uma prioridade sendo muitas vezes feita apenas no final do período pois eles acreditam na necessidade de se passar o plantão com todos os pacientes limpos. Aqui, o que importa é o retrato bonito e limpo do serviço executado e não a satisfação das necessidades básicas destes pacientes.

Um outro fator que não pode deixar de ser mencionado e que prejudica ef etivamente o desenvolvimento do trabalho da equipe de enfermagem é a deficiência e/ou precariedade dos materiais assim como a qualidade insuficiente dos medicamentos.

Os autores observaram que os registros são feitos em geral em duas etapas: a primeira, após a execução das "tarefas" relativas às $22 \mathrm{~h}$ e a segunda após a execução das "tarefas" pertinentes à $6 \mathrm{~h}$. Ora, a isto equivale dizer que os registros são feitos após a execução de todas as tarefas. A consequência direta deste fato é que, provavelmente, os registros que traduzam observação direta guardem pouca relação com a fidelidade, sejam imprecisos e pouco detalhistas.

Se uma observação não é registrada imediatamente após sido feita o tempo e o cansaço se encarregarão de apagar da memória detalhes por vezes muito importantes. Assim só os registros que traduzem execução de tarefas seriam provavelmente os mais fiéis mas também sof rem a influência tanto do tempo quanto do cansaço. É o que ocorre muitas vezes com determinados medicamentos e/ou cuidados prescritos que são checados sem serem feitos e/ou vice-versa.

Em síntese os registros são pobres e poucos e quase nunca trazem referência ao aspecto emocional do paciente. Entretanto, as enfermeiras ao mesmo tempo que valorizam os registros também os criticam quanto a sua veracidade e pouca riqueza de detalhes. Até porque os registros são a maior prova que se tem do trabalho realizado.

0 grupo estudado como um todo deixou claro a necessidade de um horário de descanso para as equipes de enfermagem que trabalham à noite. Acredita-se que este é um assunto-problema que não é pertinente apenas ao hospital alvo da pesquisa. As condições de trabalho do S.N. precisam ser revistas. 0 horário de descanso necessita deixar de ser oficioso para se tornar of icial. Deve haver um local adequado para essa situação onde o funcionário seja protegido na sua saúde.

Quando uma enfermeira afirma que o descanso deve acontecer após analizar-se as condições da unidade ela revela uma visão empresarial onde tudo deve ser feito para o bem do serviço, negando-se a reconhecer que quem faz o serviço são seres humanos.

Acredita-se entretanto que as condições de trabalho do SN mereçam estudos mais apurados.

\section{CONCLUSÃO}

0 estudo revelou que: a prática de enfermagem do serviço noturno do hospital pesquisado é mecanicista, tarefista, massificadora, que visa objetivos imediatistas e negligencia 0 atendimento da satisfação das necessidades básicas dos pacientes.

Conclui-se também que a assistência de enfermagem do SN é dividida em dois horários distintos quais sejam: de $22 \mathrm{~h}$ e $6 \mathrm{~h}$.

Detectou-se que existem cuidados de enfermagem e medicações prescritas que não são implementadas, mas são checadas e/ou registradas sem que se pudesse diagnosticar a existência ou não de critérios que norteassem essa exclusão.

\section{REFERÊNCIAS BIBLIOGRÁFICAS}

1 CARVALHO, Vilma \& CASTRO, Ieda Barreira Reflexões sobre a prática da Enfermagem. In: CONGRESSO BRASILEIRO DE ENFERMAGEM, 34, Fortaleza, 1979. Anais... Brasília, 1979 p. $51-60$.

2 HORTA, Vanda de Aguiar Processo de Enfermagem. São Paulo, EPU/EDUSP, 1973. 100p.

3 KRON, Thora. Manual de Enfermagem. 4. ed. Rio de Janeiro Interamericana 1978. $21 \mathrm{p}$.

4 SANTOS, Iraci. Análise Técnica de Supervisão. Rio de Janeiro, 1985. $67 \mathrm{p}$. 